step from an enormous dose of powdered Peruvian bark to a gelatin capsule of quinin, and even within a few years great progress has been made from the original nauseous and bulky pepsins, of only strength enough to digest a few grains of albumin, to the high power pepsins now produced without any special effort.

Another problem which should receive very careful attention is whether or not pancreatic extracts should be standardized by the same tests as vegetable diastase. I am convinced that, while we may get good results in certain cases from the use of pancreatic extracts, we can not depend on a definite diastasic action which is or should be similar to that of ptyalin, for we must remember that nature places the amylopsin of the pancreatic juice and the other various duodenal enzymes below the stomach, and they are intended more for completing and finishing the changes already begun by ptyalin before the peptic digestion supervenes. In other words, they are not intended by nature for beginning the conversion in the stomach, but act, we might say, on the food mass later, when it has an acid reaction, during the time it is being changed from an acid to an alkaline reaction, instead of on the alkaline or neutral mass when it is being changed into an acid condition, as is the function of the ptyalin, and therefore we should consider vegetable diastase supplementary to ptyalin, acting on the starch preliminarily and not secondarily.

Should we not go still further and ask that a definition be made as to what constitutes a malt extract, so as to be able to make the proper distinction between the semi-solid malt extracts and their attenuations, which contain diastase, and the liquid malt extracts, so-called, which do not?

102 West 93d Street.

Discussion,

Dr. E. T. Stewart of Detroit-As this paper brings up a question of much importance, and brings before us the results of an extended investigation, I move that a committee be appointed, consisting of the Chairman of our Section and two other members, to suggest a practical test for diastase and to recommend the same to the Committe on Revision of the United States Pharmacopeia, and that the result of their deliberations be transmitted to the American Pharmaceutical Association for its concurrence. I have myself given considerable attention to the subject, and as a result of about three thousand tests made under my direction by Prof. C. C. Sher rard, a competent chemist, I may report that we found a great variety of methods in use and corresponding differences in the results. Active diastase has great starch-transforming power ; for instance, a few grains are sufficient to convert all the starch taken in an ordinary meal by an adult in the period of les than a minute of time. Many of the preparations said to contain diastase have no starch-digesting power whatever. Every thing depends, therefore, on the quality of the diastase, and some regulation is urgently needed so as to enable the physician to differentiate between the true diastase preparations and those which are falsely alleged to contain diastase.

Dr. F. R. STODDaRD of Shelburne, Vt. - I am impressed with the importance of the positive determination of the digestive power of diastase and preparations which claim to have diastasic power, and of the necessity of the establishment of some uniform test by authority of the pharmacopeia. This is a question which should interest every physician who prescribes these remedies. The manufacturer, under present conditions, sends out these preparations, and the physician uses them, expecting them to fulfil the claims of the manufacturer and do a certain amount of work in the digestion of starchy foods, but at present he has no means of knowing whether these claims are true or false. I therefore heartily second the propo sition that a committee be appointed to report on the feasibil ity of the adoption of a uniform test for diastase.

1 Medical News, Feb. 6, 1897, p. 167

2 Boston Medical and Surgical Journal, Dec. 31, 1896, p. 669; Albany Medical Annals, March, 1895.
Dr. W. B. HILl of Milwaukee, Wis.-This is a question of great importance. It is a subject which should engage our attention as physicians who prescribe these preparations; and we should have better knowledge of their digestive or diastasic value. We need it especially, because the American people suffer from what may be called amylolytic indigestion, owing to a number of contributing causes. In the first place, there is so much starch in our food; and in the second, owing to hasty deglutition, there is a deficiency of ptyalin. There is, therefore, a great demand for diastase and preparations which assist in the digestion of starchy foods, and there is no doubt that some form of diastase will be introduced in the next pharmacopeia, and a higher test should be established and a standard be made before its introduction. It is well for us to take it up and give it due consideration at the present time, so that we may offer some well matured suggestions to the Committee on Revision, either at this or our next meeting.

Dr. F. WoodBuRx of Philadelphia-The chemistry of the digestive processes is now so well understood by physicians that the form of dyspepsia characterized by deficient amylolytic power in the secretions is now generally recognized. As a result, physicians no longer prescribe pepsin for all conditions of imperfect digestion, but they differentiate the cases in which a starch-transforming ferment will afford the desired relief from those in which the proteid digestion is at fault. Therefore, measures to promote the secretion of saliva. and of the pancreatic and intestinal juices, are recommended, and there is a constantly increasing demand by the profession for starch transforming ferments. It is most important, therefore, that some uniform test should be formulated by the biologic chemists, which may enable us to distinguish between the physiologically active and the inert, or fraudulent, diastasic preparations offered to us by the manufacturers.

Dr. R. Harcourt A nDERson of New York-I would ask Dr. Fite as to the effect of increased secretion of gastric juice upon the action of diastase. Does hypersecretion and increased acidity retard or prevent the action upon starch? If so, what measures may be adopted to overcome this difficulty?

Dr. FITE-In reply to Dr. Anderson, I would say that an increase in the acidity of the gastric juice will retard the action of diastase in the stomach. In cases of hyperacidity, it is necessary to administer an alkali before the meal, and then by the use of diastase taken with the food, we can overcome this difficulty and relieve the symptoms. The reason why so many physicians have failed to relieve patients suffering from starchy indigestion is owing to the existence of this condition of hyperacidity and their neglect to administer the alkali before meals. It is, however, true that a moderate degree of acidity does not inhibit the action of diastase. Bicarbonate of sodium, in ten to twenty grain doses immediately before each meal, will be of great assistance to the action of the diastase taken during the meal.

Six years ago, when I first took up the study of this subject, diastase was practically unknown to a majority of practitioners, whereas now it is used to a great extent by physicians all over the world. The loss of saliva by tobacco-chewers, the defective mastication of food and the limited secretion in young children, with the great proportion of starch in our food, as pointed out by our Chairman, contribute to make diastase and its preparations prominent in therapeutics, and there should be some method of standardizing these products, or of ascertaining the real value of diastase by some practical and convenient test by authority, so that there should be some uniformity on the subject.

The Chairman, Dr, Hill, put the motion, which was adopted unanimously, and appointed to serve on the committee with him Dr. Fite of New York and Dr. Stewart of Detroit.

\section{IMPROVED METHOD OF COCAIN ANESTHESIA.}

A REPLY TO A KINDLY CRITICISM OF THE AUTHOR'S

METHOD OF ANESTHESIA, BY J. F. OAKS, PH.C.,

$$
\text { M.D., PUBLISHED IN THE JOURNAL OF }
$$
JULY 17, 1897

\section{BY P. L. ANDERSON, M.D.}

$$
\text { CHICAGO, ILL. }
$$

The object of the new method is to avoid toxic effects, allay fears of patient, saving of time and cocain to both patient and surgeon, and incidentally to bring before the profession the fact that, in the prone position, patients recover from toxic effects of 
cocain, and that if patient is cocainized in the prone/logical to contend or theorize that a tampon one-half position, and operated upon in the same position, to one inch or more in length and one-fourth to half there will be no toxic effects of the drug so long as an inch in width, in close contact with two or more that position is maintained. With this brief state- parts of the nasal cavity, and remaining there for fifment of facts from the original article I will reply to teen to twenty minutes, will produce less toxic effects the Doctor's criticisms in the same order as he pre- than the application of a 25 per cent. cocain solution sents them.

The preliminary use of the one-tenth per cent. cocain spray solution is no essential factor in the ultimate anesthesia of the nasal mucosa; its purpose is merely to allay the hypersensitiveness of the mucous membrane preceding the application of the 25 per cent. cocain solution on a cotton wrapped probe. It is simply a nice, pleasant way of introducing a very disagreeable subject. To touch or rub the nasal mucosa with any foreign substance without some previous spraying of a weak solution of cocain causes a disagreeable tickling sensation, more or less pain, while a certain amount of fear takes possession of the patient's mind, which keeps him on the qui vive until the operation is completed. $\mathrm{He}$ is constantly expecting more trouble because he was hurt at the preliminary step of the operation. I use the Davidson spray tubes, and with the improved instantaneous cut-off, made by a firm in Port Huron, Mich., there is not the slightest trouble in controlling the amount of onetenth per cent. solution to be used as an initial step. As to the strength of the solution of cocain used (25 per cent.), to be candid with the gentleman who so kindly criticises my article, I privately whisper to him (of course I would not say it to anyone else) that I have for two years used a 50 per cent. solution; but in writing for publication $I$ think it poor policy to advocate such strong solutions to others, who might misunderstand my meaning or who, through carelessness or inexperience, might do much harm with such strength of solutions. Idiosyncrasies are so decided, sudden and rare that the difference between a 5 per cent. solution with tampon and 25 per cent. solution new method amounts to little or nothing, for as serious results have been reported from the use of 2 per cent., as well as $\tilde{5}$ or 10 per cent. The demonstrated clinical fact is that less cocain is absorbed into the general system by this criticised method than is done by the weak solutions with the tampon method, theories to the contrary notwithstanding. In relation to the time required in ordinary cocain anesthesia I beg to refer to no less authority than Professor Ingals of Chicago. Dr. Ingals, in speaking of cocain anesthesia in Gould's year book of treatment for 1897 says: "For intranasal operations ten to twenty minutes or more is required for cocain anesthesia."

It might be of interest to learn that since the publication of the original paper, the author has in several test cases succeeded in producing complete anesthesia for acid or galvano-cautery in one and one-half minutes, using a 50 per cent. solution of cocain. The shorter the time required for anesthesia, the less is the toxic effect. In comparing the tampon method with the author's method, Dr. Oaks forgets that the tampon, in order to retain its position in the nose, necessarily presses just as much against the septum as it does against the turbinated body, which produces the absorption of double the amount of cocain required. Again, acid and galvanic cauteries cover but small spaces, sometimes a mere dot no larger than the letter $O$ in the title of this article; often it is but a line, one-eighth to one-sixteenth of an inch in width, and from alf from a half to an inch or more in length. It is not and many well known physiologic facts reviewed, but 